\title{
KEMAMPUAN ORANGTUA DALAM MELAKUKAN STIMULASI PERKEMBANGAN PSIKOSOSIAL ANAK USIA PRASEKOLAH
}

\author{
Siti Lestari ${ }^{1}$, Livana $\mathbf{P H}^{\mathbf{2}^{*}}$ \\ ${ }^{1}$ Program Studi Ilmu Keperawatan, STIKES Telogorejo Semarang \\ ${ }^{2}$ Program Studi Ilmu Keperawatan, Sekolah Tinggi Ilmu Kesehatan Kendal \\ *livana.ph@gmail.com
}

\begin{abstract}
ABSTRAK
Perkembangan psikososial anak usia prasekolah perlu dilakukan stimulasi agar anak mencapai perkembangan psikososial yang normal. Pelaksanaan stimulasi perkembangan psikososial anak usia prasekolah tidak terlepas dari peran orangtua. Penelitian bertujuan untuk mengetahui kemampuan orangtua dalam melakukan stimulasi pada anak usia prasekolah. Penelitian ini merupakan penelitian kuantitatif dengan metode deskriptif analitik. Populasi peelitian ini adalah orangtua anak usia prasekolah di TK Kecamatan Kota Kendal dengan sampel berjumlah 72 orang. Data hasil penelitian dianalisis menggunakan distribusi frekuensi. Hasil penelitian menunjukkan bahwa mayoritas orangtua mampu melakukan stimulasi perkembangan psikososial berupa melibatkan anak membantu pekerjaan rumah ibu/ ayah, memotivasi anak bermain dengan teman sebaya dengan permainan sesuai jenis kelamin, dan memotivasi anak membantu pekerjaan sederhana di rumah (merapikan mainan, meletakkan mainan pada tempatnya).
\end{abstract}

Kata kunci: kemampuan orangtua, anak usia prasekolah, perkembangan psikososial

\section{THE RELATIONSHIP OF PSYCHOSOCIAL DEVELOPMENT WITH SCHOOL-AGE LEARNING ACHIEVEMENT}

\begin{abstract}
Psychosocial development of preschool children needs to be stimulated so that children achieve normal psychosocial development. The implementation of stimulation of the psychosocial development of preschoolers is inseparable from the role of parents. The study aims to determine the ability of parents to do stimulation in preschool children. This research is a quantitative research with descriptive analytic method. The study population was parents of preschoolers in Kendal City District Kindergarten with a sample of 72 people. Research data were analyzed using frequency distribution. The results showed that the majority of parents were able to stimulate psychosocial development in the form of involving children helping homework mom / dad, motivating children to play with peers with games according to sex, and motivating children to help simple work at home (tidying toys, putting toys in place) .
\end{abstract}

Keywords: parental abilities, preschool children, psychosocial development

\section{PENDAHULUAN}

Anak usia prasekolah merupakan individu yang berusia 3 hingga 6 tahun. Anak usia prasekolah memiliki memiliki potensi yang cukup besar untuk segera berkembang, potensi tersebut akan terus berkembang, jika anak terus dilatih untuk diberikan stimulasi (Keliat, 2015). Anak usia prasekolah akan mengalami perkembangan psikososial untuk belajar berinteraksi dengan orang lain, berfantasi dan berinisiatif, pengenalan identitas kelamin, meniru.
Soetjiningsih (2010) menyatakan bahwa pertumbuhan anak usia prasekolah dapat optimal apabila anak diberikan stimulasi untuk memrangsang seluruh aspek perkembangan anak. Fase perkembangan psikososial pada anak usia prasekolah merupakan inisiatif dan rasa bersalah. Perkembangan ini diperoleh dengan cara bereksplorasi terhadap lingkungan sekitarnya. Perkembangan anak usia pra sekolah dapat mengalami penyimpangan 
apabila tidak diberikan stimulasi. Perkembangan psikososial anak usia pra sekolah yaitu anak suka mengkhayal dan kreatif, anak punya inisiatif bermain dengan alat-alat di rumah, anak suka bermain dengan teman sebaya, anak mudah berpisah dengan orang tua, anak mengerti mana yang benar dan yang salah, anak belajar merangkai kata dan kalimat, anak mengenal berbagai warna, anak membantu melakukan pekerjaan rumah sederhana, anak mengenal jenis kelaminnya, belajar ketrampilan baru melalui permainan (Worshop keperawatan jiwa, 2015).

Data Riskesdas (2018) menyebutkan bahwa perbandingan indeks perkembangan anak usia 36 hingga 59 bulan di Indonesia mencapai $88,3 \%$. Data ini lebih rendah dibandingkan Thailand, Vietnam, dan Kazakhtan. Sedangkan anak prasekolah yang mengalami gangguan pertumbuhan dan perkembangan di Kabupaten Kendal pada tahun 2013 terdapat sebanyak1.136 (DKK Kendal, 2013). Penelitian Adriana (2011) menunjukkan bahwa perkembangan anak membutuhkan stimulasi. Anak yang mendapat stimulasi yang teratur dan terarah akan lebih cepat berkembang dibandingkan dengan anak yang kurang mendapat stimulasi.

Penelitian PH dan Anggraeni (2018) menyatakan bahwa anak cenderung mengalami kekerasan baik fisik maupun verbal yang dilakukan oleh orang tua, karena pada usia tersebut anak mulai nakal dan orang tua menggunakan metode kekerasan untuk mendisiplinkan anak supaya anak tidak nakal. Hal ini terjadi karena kekurangtahuan orangtua dalam mengasuh dan menstimulasi anak.

Orang tua sangat berperan dalam melakukan stimulasi bagi proses perkembangan anak secara keseluruhan sehingga orang tua dapat sedini mungkin mengenali mengenali kelainan proses perkembangan pada anaknya (Soetjiningsih, 2010). Studi pendahuluan yang dilakukan pada salah satu TK di Kecamatan Kendal didapatkan dari 7 dari 9 anak yang dilakukan pengkajian awal mempunyai perkembangan psikososial yang normal. Penelitian terkait kemampuan orangtua dalam melakukan stimulasi perkembangan psikososial pada anak usia pra sekolah belum pernah dilakukan, sehingga penelitian ini perlu dilakukan agar dapat mendiskripsikan pencapaian perkembangan psikososial anak usia sekolah yang normal. Penelitian ini bertujuan untuk mengetahui kemampuan orangtua dalam melakukan stimulasi perkembangan psikososial usia pra sekolah melalui penelitian kuantitatif.

\section{METODE}

Penelitian ini merupakan penelitian kuantitatif dengan pendekatan deskriptif analitik. Populasi penelitian ini adalah anak usia pra sekolah di TK Kecamatan Kota Kendal dengan jumlah sampel 72 orangtua. Alat pengumpul data dalam penelitian ini menggunakan kuesioner terkait kemampuan orangtua dalam melakukan stimulasi perkembangan psikososial usia pra sekolah. Data hasil penelitian dianalisis secara univariat menggunakan distribusi frekuensi.

\section{HASIL}

Hasil penelitian terkait karakteristik disajikan pada tabel 1 berikut ini:

Tabel 1.

Karakteristik responden $(\mathrm{n}=72)$

\begin{tabular}{lcc}
\hline Variabel & f & \% \\
\hline Jenis kelamin & & \\
Laki-laki & 13 & 18 \\
Perempuan & 59 & 82 \\
\hline Pendidikan & & 3 \\
SD & 2 & 11 \\
SMP/MTS & 8 & 80 \\
SMA/MA & 58 & 3 \\
D3 & 2 & 3 \\
S1 & 2 & \\
\hline
\end{tabular}


Hasil penelitian menunjukkan rata-rata usia responden 32 tahun, usia termuda 24 tahun, usia paling tua 36 tahun, dengan standar deviasi 5,054.
Hasil penelitian menunjukkan bahwa mayoritas responden berjenis kelamin permpuan dan berpendidikan terakhir SMA/MA.

Tabel 2.

Kemampuan orangtua dalam melakukan stimulasi pada anak usia prasekolah $(\mathrm{n}=72)$

$$
\text { Kemampuan orangtua }
$$

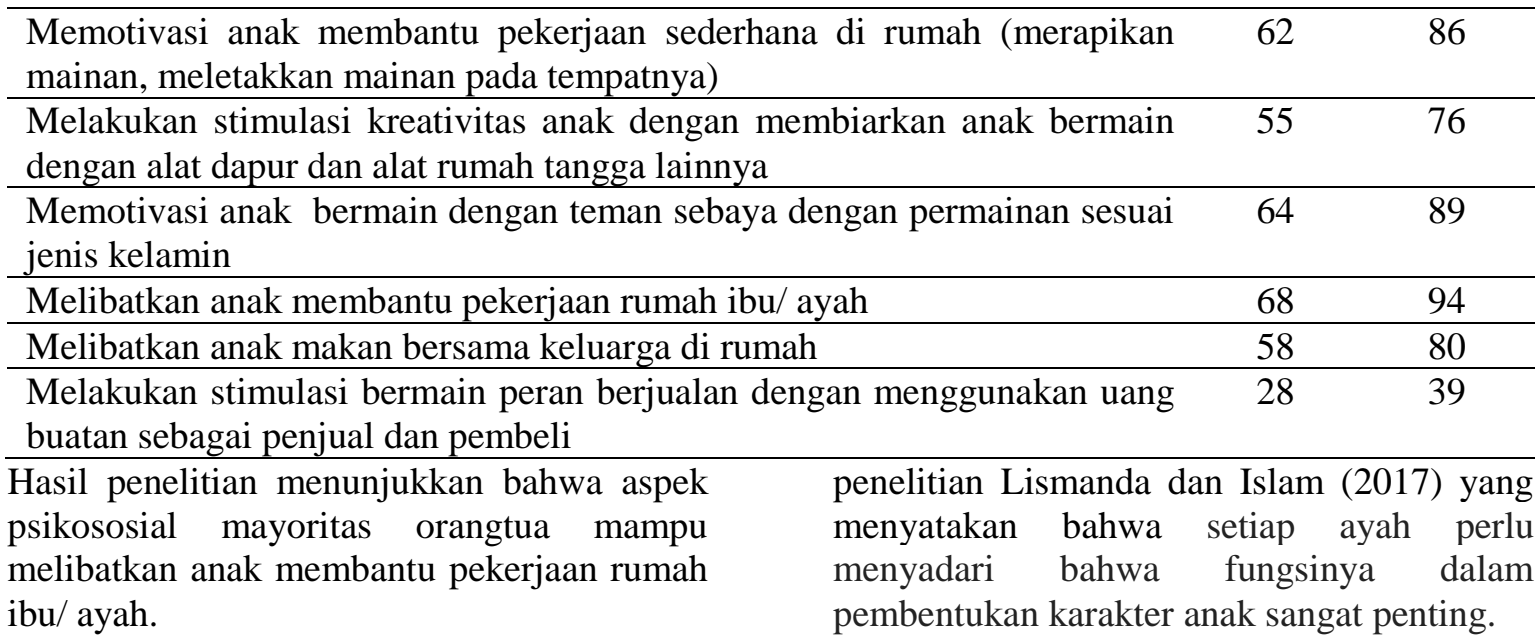

\section{PEMBAHASAN}

Hasil penelitian menunjukkan bahwa rerata usia responden 32 tahun. Usia 32 tahun merupakan tahap usia dewasa dimana pada tahap ini seorang individu berapa pada tahap produktif. Individu dengan usia dewasa dalam tahap perkembangan psikososial akan membentuk suatu rumah tangga yang akan mendidik anak-anknya sebagai penerus di masa yang akan datang. Proses mendidik anak tentunya tidak jauh dari perilaku yang ditunjukkan orangtua terhadap anak. Hasil penelitianyang pernah dilakukan .... bahwa pengaruh pengasuhan terhadap perkembangan moral anak usia kurang dari 4 tahun dipengaruhi perkembangan karakter anak, seperti keharmonisan keluarga, yang menjadi faktor pendorong terjadinya stimulus tak langsung melalui perbuatan dan perilaku nyata yang dicontohkan oleh kedua orang tuanya.

Hasil Penelitian menunjukkan bahwa minoritas responden adalah laki-laki. Hasil ini menunjuikkan bahwa seorang ayah juga mempunyai peran penting dalam perkembangan psikososial anak usia prasekolah. Hasil ini sejalan dengan
Hasil penelitian terkait kemampuan orang tua dalam melakukan stimulasi kreativitas anak dengan membiarkan anak bermain dengan alat dapur dan alat rumah tangga lainnya sebesar 76\%. Hasil ini sesuai hasil penelitian Erfayliana (2016) bahwa aktifitas bermain bagi anak yang melibatkan gerak anak seperti yang terdapat pada permainan tradisional yaitu bermain dangan alat dapur, mempunyai pengaruh yang positif terhadap pertumbuhan dan perkembangan anak, khususnya perkembangan jasmani anak.

Hasil penelitian menunjukkan bahwa kemampuan orangtua dalam memotivasi anak bermain dengan teman sebaya dengan permainan sesuai jenis kelamin mencapai $89 \%$. Hasil ini sejalan dengan penelitian Suharto, Mulyana, dan Nurwati (2018) bahwa pengaruh teman sebaya sangat besar terhadap individu tersebut, sehingga individu yang tidak diasuh oleh kedua orang tunya cenderung mempunyai identitas yang negatif, demikiab sebaliknya bahwa individu yang diasuh orang tuanya akan memiliki identitas yang positif dengan tetap memotifasi anak bermain dengan teman sebayanya. Hasil penelitian ini memperkuat penelitian 
Erfayliana (2016) bahwa melalui aktifitas bermain dengan teman sebaya individu akan mendapatkan kesenangan dan juga kepuasan diri.

Hasil penelitian terkait kemampuan orangtua dalam melibatkan anak makan bersama dirumah mencapai $80 \%$. Hal ini dilakukan orangtua sebagai salah satu aktifitas fisik yang dapat dilakukan anak bersama orangtua. Hasil ini mendukung penelitian Jade, Steven, Stewart, Rute, Dylan (2018) bahwa aktifitas fisik dan mendukung partisipasi dalam olahraga yang terorganisir dapat menjadi target yang layak untuk perkembangan kognitif dan psikososial pada anak-anak prasekolah. Penelitian yang dilakukan Marta, Javier, Vladimir, Ana (2018) .menyebutkan bahwa aktifitas fisik lain yang dapat dilakukan orangtua terhadap anak untuk meningkatkan perkembangan psikososial yaitu dengan memilih alat transportasi anak usia prasekolah saat pergi kesekolah yaitu dengan bersepeda.

Hasil penelitian terkait kemampuan orangtua melakukan stimulasi bermain peran berjualan dengan menggunakan uang buatan sebagai penjual dan pembeli menunjukkan frekuensi yang sangat rendah yaitu $39 \%$. Hal ini menunjukkan bahwa saat ini aktifitas bermain peran anak usia toddler jarang dilakukan, karena orang tua juga jarang melakukan stimulasi bermain peran. Hasil ini sejalan dengan penelitian setianingsih (2018) bahwa anak lebih banyak menggunakan gadged dibanding bermain dengan aktifitas fisik yaitu $81,1 \%$ anak menggunakan gadget $<2$ jam perhari. Hasil Penelitian Imron (2017) menyatakan bahwa ada hubungan penggunaan gadget dengan perkembangan sosial dan emosional anak prasekolah. Berdasarkan beberapa hasil penelitian tersebut maka penting bagi orangtua untuk memberikan pengawasan dan stimulasi pada anak dalam bermain peran agar anak dapat terhindar dari dampak penggunaan gadget.

\section{SIMPULAN DAN SARAN \\ Simpulan}

Orangtua anak usia prasekolah mayoritas memiliki kemampuan dalam melibatkan anak membantu pekerjaan rumah ibu/ ayah.

\section{Saran}

Hasil penelitian ini dapat digunakan sebagai data dasar dalam penelitian selanjutnya, sehingga peneliti berharap peneliti selanjutnya dapat melakukan penelitian dengan memberikan intervensi dalam melalukan stimulasi pada anak, khususnya anak usia prasekolah.

\section{DAFTAR PUSTAKA}

Adriana. (2011). Tumbuh Kembang dan Therapy Bermain pada anak. Jakarta: Salemba Medika

DKK Kendal. (2013). Data ganguan pertumbuhan pada anak. Kendal

Erfayliana, Y. (2016). Aktivitas Bermain Dan Perkembangan Jasmani

Anak. Terampil: Jurnal Pendidikan dan Pembelajaran Dasar, 3(1), 145158.

https://doi.org/10.24042/terampil.v3i1. $\underline{1334}$

Hastuti, D. (2009). Stimulasi psikososial pada anak kelompok bermain dan pengaruhnya pada perkembangan motorik, kognitif, sosial emosi, dan moral/karakter anak. Jurnal Ilmu Keluarga \& Konsumen, 2(1), 41-56. http://doi.org/10.24156/jikk.2009.2.1.4 1

Imron, R. (2018). Hubungan Penggunaan Gadget dengan Perkembangan Sosial dan Emosional Anak Prasekolah di Kabupaten Lampung Selatan. Jurnal Ilmiah Keperawatan Sai Betik, 13(2), 148-154.

http://dx.doi.org/10.26630/jkep.v13i2. 922

Jade McNeill, Steven J. Howard, Stewart A. Vella, Rute Santos, Dylan P. Cliff, Physical activity and modified organized sport among preschool children: Associations with cognitive and psychosocial health, Mental Health and Physical Activity, Volume 
15, 2018, Pages 45-52, ISSN 17552966,https://doi.org/10.1016/j.mhpa.20 $\underline{18.07 .001}$

Keliat, B. A. (2015). Keperawatan Kesehatan Jiwa Komunitas. Jakarta : EGC.

Lismanda, Y. F., \& Islam, P. G. R. A. U. (2017).

PONDASI

PERKEMBANGAN PSIKOSOSIAL ANAK MELALUI PERAN AYAH DALAM KELUARGA. Viractina: Jurnal Pendidikan Islam, 2(2), 89-98. http://riset.unisma.ac.id/index.php/fai/a rticle/view/826

Livana, P. H., \& Anggraeni, R. (2018). Pendidikan kesehatan tentang perkembangan psikososial sebagai upaya pencegahan kekerasan fisik dan verbal pada anak usia sekolah di Kota Kendal. Jurnal Ners dan Kebidanan (Journal of Ners and Midwifery), 5(2), 097 -

104.DOI: 10.26699/jnk.v5i2.ART.p09

7-104

Marta Terrón-Pérez, Javier Molina-García, Vladimir E. Martínez-Bello, Ana Queralt. Active commuting to school among preschool-aged children and its barriers: An exploratory study in collaboration with parents. Journal of Transport \& Health, Volume 8, 2018, Pages 244-250, ISSN 2214-1405,

Setianingsih, S. (2018). Dampak penggunaan gadget pada anak usia prasekolah dapat meningkatan resiko gangguan pemusatan perhatian dan hiperaktivitas. Gaster: Jurnal Kesehatan, 16(2), 191-205. https://doi.org/10.30787/gaster.v16i2.2 $\underline{97}$

Soetjiningsih. 2010.Tumbuh Kembang Remaja dan Permasalahannya. Jakarta :SagungSeto.

Suharto, M. P., Mulyana, N., \& Nurwati, N. (2018). Pengaruh Teman Sebaya Terhadap Perkembangan Psikososial
Anak TKI di Kabupaten

Indramayu. Focus: Jurnal Pekerjaan

Sosial, 1(2),

135-147.

https://doi.org/10.24198/focus.v1i2.18 $\underline{278}$

Worshop keperawatan jiwa. (2015). Standar asuhan keperawatan jiwa. Gangguan resiko dan sehat. Universitas Indonesia. 
Jurnal Ilmu Keperawatan Jiwa Volume 2 No 3, Hal 123-128, November 2019

Persatuan Perawat Nasional Indonesia Jawa Tengah 